\title{
Wishful Images: Three Cinematographic Portraits of a National Film Company
}

\section{Anne Kerlan, Director of research, CNRS}

The Center for studies on China, Korea and Japan

Centre National de la recherche scientifique-French National Centre for Scientific Research

École des Hautes Études en Sciences Sociales-the School of Advanced Studies in the Social

Sciences

Université de Paris

\begin{abstract}
This paper explores how the Lianhua Film Company, founded in 1930 and active until 1937, communicated its identity and project through its films. These drama films offered an idealized portrait of the movie world and the Chinese society, revealing how the company's members defined their role in a society looking to build a national identity.

The paper focuses on three films: Two Stars of the Milky Way (1931) was a cinematographic interpretation of the founding statement of the company and depicts the company's utopia. Lianhua's Symphony (1936), composed of eight shorts, was a patriotic call to resist the Japanese enemy. A Sea of Talents (1937) was produced in the final days of Lianhua, just before the Japanese invasion. It offers a portrait of the artistic world disillusioned and far from patriotic anxieties.

These films, analysed here alongside written sources, draw a portrait of the company both as it wanted to be seen and as it actually was. Studying them illuminates the hopes, battles and disillusions of a world of professionals who projected on the screen theirs visions, sometimes conflicting, of a stronger and unified Nation.
\end{abstract}

\section{Keywords}

Republican China; film company; national product movement; film on film; Lianhua (U.P.S.)

\section{Biographical note}

Anne Kerlan is Director of Research at the CNRS (Centre National de la recherche scientifique-French National Centre for Scientific Research) since 2001. After having been a researcher at the Institut d'histoire du temps présent until 2017, she joined the The Center for studies on China, Korea and Japan (CNRS; École des Hautes Études en Sciences Sociales-the School of Advanced Studies in the Social Sciences; Universite de Paris) and is there the head of The research center on modern and contemporary China. She is a historian of twentiethcentury China, specialized on Chinese visual culture and Chinese cinema, teaching at the École des Hautes Études en Sciences Sociales for masters and $\mathrm{PhD}$ on these topics. Her publications include Lin Zhao: Combattante de la liberté (Fayard, 2018; the book won two prizes in 2019) and Hollywood in Shanghai. L'épopée des studios de la Lianhua, 1930-1948 (PUR, 2015).

Word count (including references, figures and figure captions, endnotes): 10361 words 



\section{Introduction}

The smiling face of Ruan Lingyu emerging from a star, with a drawing in red and white in the background evoking a rising sun, with the caption: 'Special issue on the Renaissance of Chinese National Cinema': it is June 1930 and the Film Magazine (Yingxi zazhi) is taking a new direction that will also be considered a turn in the history of Chinese cinema. Featuring a Chinese actress instead of an American star, with the sun (a symbol on the flag of Republican China since 1928) and also the text, all lend a new flavor to a magazine that until recently had mostly been dedicated to American and Hollywood films. The meaning is clear: just a couple of years after the installation of the Nationalists in Nanjing, while the government was insisting on the role of business and industry in the development of a national culture, Chinese cinema wants to participate in the building of a strong nation.

At the very end of that issue is an announcement signed by Huabei film company producer, Luo Mingyou; a call for a project operated by professionals who will be organized in a national network that would become the Lianhua film company (or United Picture Services, U.P.S.), officially founded at the beginning of 1931.

Lianhua was not just another film company. It was a playground for a group who believed they had something to contribute to the construction of a new China. Its founders entrepreneurs, statesmen or artists - were members of the Chinese urban bourgeoisie, they all believed that culture could contribute to building a new China. And Lianhua was a tool for this purpose. As such, promoting the company project was important. Photos, articles, interviews in the Film Magazine and other newspapers offered strategic communication about the company. Soon, films also encapsulated its founders' ideals.

This article explores how this movie company advertised itself and promoted its identity through a certain genre of films: films describing the movie industry. We focus on three movies made at the two ends of the company's history. Two Stars of the Milky Way (Yinhan 
shuangxing, Shi Dongshan, 1931) was a filmic interpretation of the company's founding statement; Lianhua's Symphony (Lianhua jiaoxiang qu, collective, 1936), was a patriotic call to resist the Japanese enemy; while $A$ Sea of Talents (Yinhai fengguang, collective, 1937), was an entertaining film about the art world produced just before the Japanese invasion. Comparing these films tell us about the company's evolution as well as about the changes in its ideological project.

As has been shown for Hollywood, advertising was central to the early development of films. Advertising is about more than just selling products. It has a normative function: 'advertising as a discourse created standards and exploited innovations. It established [...] prescriptive values which became requirements for film practice.' (Bordwell and al. 1985, 98-102). The same way, these three Lianhua films are both a product and entertainment sold by the company, and a visual message communicating the company's values. The hope, the belief, was that the films and their message could offer a new visual identity of the Chinese movie world that will contribute to transform the Chinese society.

These films, however, are fiction, and so is their portrait of the company. Comparing them with written sources, we can thus see the film company both as it wanted to be seen and as it really was. However, image is a construction - but so is text. The dynamic between the filmic and textual representations is more complex than an opposition between the fictional and the real; the challenge here is to combine dissimilar sources without opposing them. This way of writing history hopefully creates new understandings of the past. As Christian Henriot and Wen-hsin Yeh put it: 'With movies — which create a world of fiction and elaborate intricate narratives - the historian needs to filter his own inquiry and insert the visual document into its appropriate social context' (Henriot \& Yeh 2013, XXIII). The social context for Lianhua company was the building of a new, young Chinese nation, under the Guomindang government. This study will show how Lianhua's goal links with the national project 
undertaken during the Nanjing era and how the three films also echo this relation to the national, though in different manners.

\section{Two Stars of the Milky Way, a Showcase of the Chinese Movie World}

Producers and directors are gathered around a rectangular table in an elegant room. On the wall is a photograph of a compact block of company buildings whose layout and appearance evoke Hollywood film studios. In the meantime, the production board announces the company's goals: 'We in the film industry have a mission to fulfill, that of propagating the virtues of our people and of imparting knowledge to the public through the screen'.

(Fig. 1)

This is Two Stars, one of the first productions of the young film company Lianhua that was officially registered in Hong Kong on 25 October, 1930. ${ }^{1}$ The film could be seen as the company's illustrated birth announcement. It paints a company portrait, building a world in images, a projection of the values and aims of Lianhua's entrepreneurs. It is a visual manifesto of a newborn company.

Two Stars was produced between May and September 1931 (Lu 1/5-13/12/1931), at Lianhua's Shanghai Studio Two ${ }^{2}$. One of the first sound films of Lianhua (using sound on disc technology), Two Stars was an entertaining opus about the movie world that drew on the MGM musical Show People (Ban 1932, 30). It was an expensive, prestigious production as shown by the heavy advertisement campaign that lasted from the autumn until the premier at the Nanjing Theater in Shanghai on December 13, 1931.

From the opening credits of the film, its ambition is obvious. Intertitles associating Chinese and English, in an art deco design, present a stellar team. Many of them are already well known, including the lead female role, played by a Cantonese musical star, Violette Wong Zi Luolan (Harris 2012, 199, 208) or actor Jin Yan (Raymon King), nicknamed the 'Chinese 
Rudolf Valentino'. Also introduced is the newly-acquired singing and dancing troupe of Lianhua, here called 'U.P.S. Follies'. ${ }^{3}$ In addition, some important personalities from the company such as directors Sun Yu, Wang Cilong and Cai Chusheng, are extras in the film. Even the composers are prestigious featuring one great musician of the time, Li Jinhui.

The participation of the U.P.S. Follies, the choice of singer for the lead role, and action located in artistic circles signal that this film is following the canon of the musical comedy genre, which was very popular among Shanghai audiences. The sumptuous sets by Fang Peilin mix art deco design and oriental motifs, evoking both American musicals and also the refined luxury Shanghai cabarets aimed at the Chinese urban upper middle class (Harris 2012, 238; Jones 2001, 69).

The screenplay was based on a novel by Zhang Henshui published as a serial in 1928-1929 (Gao 2009, 38-39). Two Stars tells the story of a young girl, Yueh Ying, living in seclusion in a beautiful villa in the countryside with her father, a famous composer. A team from the Yen Han company (hereafter in Yinhan) discovers this rare gem and hires her to perform in the film adaptation of the Cantonese opera Sorrow in the Eastern Pavilion (Lou dong yuan). With the leading actor Yee Yun, she forms an ideal couple and both the producers and the girl's father hope for a marriage between them. What they don't know is that the actor is already married. A sense of filial piety blocks him from divorcing the woman his parents chose; nor can he sully Yueh Ying's reputation by making her his second wife. So, he chooses to 'sacrifice' himself by purposefully making his young colleague believe he is untrustworthy. When she catches him fooling around with another woman, Yueh Ying resigns and returns to the countryside with his father. Some time later, Yee Yun goes there, and the film ends on a sad scene, the young man listening to the one he still loves, but not revealing his presence. Two Stars is a movie about the moviedom. The genre is not new. In Hollywood - the main model for filmmaking in 1930's China - the genre goes back to at least 1908 (Cieutat 1984, 
62) and developed into a typical romance about a 'dreamer who comes to Hollywood in search of stardom and finds only poverty and exploitation' (Ames 1997, 22). In China too, many films depicted the Shanghai film world. However, unlike Hollywood or previous Shanghai films ${ }^{4}$, Two Stars does not focus on the story of the struggle of a wannabe star but rather centers on the movie world itself, offering an insight into how a Chinese film company works.

The Yinhan Company is described as a modern company, arranged, managed and equipped on the Western model. Offices, meeting rooms and actors' dressing rooms are decorated with refinement; producers and directors are dressed in tuxedos and smoking cigars. The photography of the studios, and filmset with its cameras and projectors, underline the technical modernity of the company. The world of cinema is closely associated with the most innovative communication technologies, whether radio or telephone: indeed director Wang has no less than four telephones on his desk!

The various trades in this industry also demonstrate technical modernity; their know-how and specialized skills are presented. They are however, interestingly, shown as the backgrounds of an elegant, artistic or intellectual activity. The camera's skills are also demonstrated, for instance in the scene of the make-up which offers an opportunity for a visual play with the reflection of the actors in the mirrors. The general view of the filmset of Sorrow in the Western Chamber is revealed through a traveling-out movement. Through these exhibitionist moments, typical of a 'cinema of display', filmmaking is shown as a skillful and elegant art. But parallel to these images of the modernity of the film industry, we witness a demonstration of the moral rigor which inhabits this world. Film-making is described a collective process, a joint mission where everybody has an assigned role, while M. Guo, the director, is portrayed as the benevolent leader of a team.

(Fig. 2) 
The company's goals are presented in the speeches from the filmmaker and producer. Filmmaking is a social task, important for the Nation: 'We should always bear in mind the importance of our mission to the community at large and the necessity of perseverance in the study and perfection of this art; we must try to improve the standard of Chinese films...'

Not only the national commitment, but also the moral value is enhanced: the Yinhan company is depicted as a family, a paternalist, protective environment for the young girl. Working there does not threaten a woman's morals, as it was perceived to by many Chinese at the time. On the contrary, the company defends her virtue and organizes her life as a good father would do for his daughter. In the banquet scene, the film director is approached to arrange what is then considered to be a perfect marriage between Yueh Ying and Yee Yun. The moral code is conservative and so is the company: a love affair needs to be sanctified according to the family's rules. Later in the film the actor Yee himself is presented as a good son and a good person, ready to sacrifice his love in order to respect his deceased mother's wishes and to prevent his girlfriend losing her social status.

In that sense, the story differs greatly from Hollywood or other Shanghainese films of the same genre. Even if Two Stars has a bittersweet ending, it avoids direct criticism of the movie environment: the main personalities of the company all end up as good people, following Confucian morals and protecting each other from downfall.

By setting a long sequence of filmed opera within a contemporary history, the film combines a strong homage to Chinese national culture with a hymn to the modernizing dynamics of the film industry. This hybrid construction is symptomatic of the self-image that Lianhua wants to convey. The Yinhan studios are a perfect world, combining professionalism and modern spirit with a sense of duty and respect for cultural traditions.

From Yinhan to Lianhua: the Project of a National Film Company 
Two Stars presents the perfect portrait of a film company and one could wonder if the film is not the description of a utopia.

Since Thomas More, and his description of the ideal society in Utopia or The Island of Nowhere printed in 1516 , the notion of utopia has widened, applying to much more than a simple literary genre, but to all kinds of social forms of expression to the point that it has been possible to define it as 'a place and a specific mode of social imagination' (Baczko 1978, 404). Utopia, articulated to speeches, could also sometimes be confused with political and social systems (Manuel, 1979, 2-3). In the core of the utopia, resides indeed this wish, to improve the society, what Ernst Bloch in The Principle of Hope designated as a "concrete utopia' contributing to the positive social change. In counterpoint, resides thus a critical posture, the utopia being drawn in counter-model of a real, unsatisfactory society or taking support on the opening towards not realized possibilities, this 'not yet', to quote again Ernst Bloch.

If utopias have diversified, the abundant literature devoted to them allows us to note some common characteristics. Among them, the importance of the 'to make believe': it is a question of making the fictive, the imaginary world pass for true, which is achieved by a detailed description of this world, in particular by an attention paid to the architectures, to the clothing (Trousson 1998, 32). The 'to make believe' is then also often based on a 'to make see', the utopia becoming then a form of total spectacle.

Two Stars has many of the characteristics of a utopian narrative: in the attention paid to the details of places, situations, and characters, everything makes us believe that we are in a real world. Like a utopian story, it opens and closes with a journey, a geographical displacement in a place uncharacterized, which also serves as an airlock between the real world and the utopia (Trousson, 1998, 26): a lovely lakeside landscape with a beautiful villa emerging from the vegetation. Finally, let us note the emphasis, specific to utopia, placed on the collective to 
the detriment of the individual in the film: everything is done collectively, from the shooting to the festivities accompanying the release of the film (Trousson, 1998, 103-114). Yueh Ying finds herself alone only once she has left the world of cinema.

Why did Lianhua propose this utopia? It is not simply a question of offering the spectators a moment of dream. It is worth underlining the link that is established between the fictional company and the real one, between the Yinhan and the Lianhua. By producing this film at the very beginning of its existence, the company offers its audience a complete and articulated image and sort of fictitious reference against which the company's achievements can be judged.

Modern and westernized: there is visual continuum between the fictive company, Yinhan, and the real one, as it was advertised. Since the beginning, Lianhua had published pictures of its founders, employees and patrons: men dressed in Western clothes, women in elegant qipao, fur coats, with hairstyles similar to that of Yueh-Ying. Lianhua's network of shareholders was indeed composed of successful Hong Kong/Canton merchants and compradors, important figures of the Chinese film industry and a few eminent statesmen. Some of them lived in mansions that could compete with Fang Peilin's settings.

It almost seems as if Lianhua tried to look like the ideal company Yinhan. However, in reality the company's milieu and environment were rather heterogeneous. In 1931, there was no such compound as the one depicted in the film; the Shanghai studios were scattered in different parts of the town. Most of the employees were living in dormitories or shared housing. Sun $\mathrm{Yu}(1987,86)$, for instance, recalls having lived in the 'dark dormitory of Studio $\mathrm{n}^{\circ} 1$ ' before moving in 1931 to a rooftop room that he shared with another Lianhua's employee.

Why did Lianhua tried so much to match the fictive, idealized company? Why presenting itself as a realization of a utopia?

It could have been a way to attract Lianhua's shareholders and patrons from the new urban 
bourgeoisie. Further, this idealized depiction helped the company project a positive image of the Chinese film industry, with its ambition to be considered an important, high-standard national cultural industry.

These ambitions were first revealed in the June 1930 issue of the Film Magazine about the Renaissance of National film industry. The idea of a Chinese cinema renaissance echoed the movement of national products that found a new start with the Nanjing government (Gerth 2003). The network of businessmen that Lianhua targeted was the same one that supported the movement: one finds among the Lianhua board of trustees Jian Yujie, one of the two founders of the Nanyang Brothers Tobacco Company (Shanghai yinhang $n^{\circ} 7265$ ). There seems to have been the sincere hope that the government would pay attention to (and support) this new entertainment industry in its efforts to become a national industry.

While the film industry was heavily dependent on Western - mainly American - models and techniques, the strategy for promoting national cinema was twofold: first, compete with Hollywood, second, rely on the Chinese morals.

To compete with Hollywood, the Chinese film industry needed to produce films with the same flavor and quality as the American features. Two Stars is an example of this. However, it was also important not to look too foreign. The film industry was not the only one that encountered this kind of contradiction and the Chinese/Foreign duality that was the criterion for national products had to be adapted to the production environment. Indeed, 'the category of national products was linked to nationalism, authenticity, and modernity, as well as to traditional concepts such as propriety brighteousness, integrity and shame. In contrast, the category of foreign products was associated with imperialism, treason, inauthenticity, weakness, and immorality' (Gerth 2003, 187). Hence the strong moral element of Two Stars. It was natural for the founders of Lianhua, in particular Luo Mingyou, to promote Chinese values. They strongly believed that film could educate people about Chinese values and about 
the modern world, and they expressed these opinions in many articles. The presentation of the mission of cinema in Two Stars was a synthesis of these ideas. In fact words that are used in Two Stars became Lianhua's logo, with its four sentences: 'Promote art; spread culture; propagate education for the people; save national industry' (Tichang yishu, xuanyang wenhua, qifa minzhi, huanqiu yingye)

(Fig. 3).

Two Stars is the projection on a screen and translation into images of the new company's goals, including its political goals. There is then a dimension of advertisement in the film, for the company as a national product or as a site for production of national products. For instance, Yinhan's film-in-a-film is a Cantonese opera. With its display of Chinese elements, Two Stars participates in creating an 'exhibitionary complex' linked to the national product movement. Since 1928, encouraged by the government, fairs, museums and other spectacles were created to show to the public the national products, to create a purely Chinese environment where people could roam and briefly experience a life away from foreign products. This created 'a specific form of socialized or culturally constructed vision, a nationalistic visuality' (Gerth 2003, 203-208) and I believe that Two Stars is Lianhua's demonstration of its will to participate in this 'nationalistic visuality'.

Film creates a moment apart from real life where the moviegoer can indulge in a world that is not only viewed but experienced in a dark room. But more than just creating an illusion, film can make viewers believe in it, as 'the photographic realism of film gives it a mimetic immediacy that exceeds the mimetic illusions of book and stage' (Ames 1997, 5). As such, one can only underline the proximity of cinema and utopia, in its illusionist power, its capacity to "make world". Ernst Bloch had noticed this, while criticizing it when this dream factory was in the service of a capitalist Hollywood: 'In general therefore the film, in that it is capable through photography and microphone of incorporating the whole of real experience in 
a streamlike mime, belongs to the most powerful mirror- and distortion- but also concentration-images which are displayed to the wish for the fullness of life, as substitute and glossy deception, but also as information rich in imagery. Hollywood has become an incomparable falsification...'(Bloch 1995, 408-9) For Bloch, another cinema is possible: ‘A good dream-factory, a camera of dreams which are critically inspiring, overhauling according to a humanistic plan, would have had, had and undoubtedly has other possibilities - and this within reality itself" (Bloch 1995, 410).

Some have noted this parallel between utopia and mass entertainment, notably Hollywood cinema. Adrian Ivakhiv, following Ernst Bloch and Michel Foucault, proposes in particular to consider cinema as a heterotopia: 'Like a mirror, cinema is heterotopic in that it presents the world to us, but differently, in a reconstituted manner, with its presentation affecting the world in heterogeneous ways' (Ivakhiv 2011, 192). Two Stars presents a perfect collectivity and idealized world where everybody seems happy to work, where the company is the right place to be, and a place safe from social and political tensions. As such, it is not just a cinematographic utopia for the Chinese film industry but, even more, a social and political utopia for Chinese Nation. But behind Two Stars and the perfect Yinhan company, there is Lianhua, the real one: a company that wishes to change the movie industry and contribute to the nation building.

Utopia was indeed part of Lianhua's project. The company two first years are rich in events, activities, publications and photos that tend to prove this. It shows how the founders of the company, who spoke on its behalf, dreamed of a society very different from the one that had been established with the arrival of Chiang Kai-shek in power, or the one the communists proposed. Like in Two Stars, they called for a harmonious society, without money, class or gender conflict, where each person in his or her place contributed benevolently to the collective good. Far from being a society in rupture with the past, notably with the Confucian 
values, it was a society which took the best advantage of it, with the naive hope that the people, carried by these values, could only be good or amendable. Culture was the essential pillar of this society, the guarantor of this social harmony.

However, the backstage of 'Lianhua's world' was quite different. The company encountered continuous financial difficulties, including during filming Two Stars. In July 1931, the producer Lu Jie asked Fang Peilin to limit expenses for the film's settings (Lu, 23/07/1931). As for the company's family spirit, it was not as harmonious as expected: many employees went to work as extras for the competitors ( $\mathrm{Lu}, 10 / 06 / 1931)$, while the director Shi Dongshan received an invitation to work for that company as well. The producer's daily life consists of financial difficulties and personnel tensions, far from the perfect world of Yinhan company. With its lavishness and celebration of the film industry's modernity, Two Stars hides the anxiety of entrepreneurs who felt that the world they wanted to build was fragile and easily threatened.

\section{Ups and Down of the Utopia}

Two Stars was still showing in Shanghai on January 27, 1932. The following day, Japan launched an attack destroying important parts of the city, including cinemas and film studios. The utopia portrayed in Two Stars - and the Lianhua Company - were confronted with an entire new reality. Lianhua, however, made great efforts to maintain the appearance of a visionary and ambitious company, in particular through its magazine, Lianhua huabao, a weekly publication in 1933 and 1934 and a bimonthly magazine from January 1935.

Lianhua tried for instance to present itself as a virtuous enterprise, working for the good of its employees. It built them dormitories and social and 'recreation clubs'. The company hoped to develop its employees' ethical and cultural spirit, and protect them against the 'poisons' of the modern world (LHNJ 33-34, 4, 6, 58). The mix of Chinese Confucian morals and westernized 
behaviors in Two Stars was indeed inherent to Lianhua. The most spectacular development was the building of an entire new compound in the Xujia hui area. The idea of building a Hollywood-type moviedom in Shanghai, similar to that seen in Two Stars, had been repeatedly announced (Shenbao, 13/03/1933, 11). First, in March 1933, the Company was restructured, and the studios were integrated into one single structure (LHHB 2.21, 2). Then, in March 1935, it was announced that all Lianhua studios would move to Xujia hui. This location was to be the biggest production site in China (LHHB 5.6, 7). The managerial structure again changed, with a more integrated structure, under the direction of Luo Mingyou.

The site of Xujia hui was presented in Lianhua's publication with many photos, as the 'cinematographic city' the company had wanted to build since its foundation (LHHB, 6.8, 13). Located on $40 \mathrm{mu}$ of land, not far from the French settlement and the Xujia hui cathedral, the compound had several shooting locations, both indoor and outdoor, alongside technical rooms and managerial offices, as well as gardens, a swimming pool and tennis courts. The offices looked quite comfortable. Depicted in photos and magazines, Xujia hui seemed the concretization of Yinhan's idyllic place. From the outside, Lianhua seemed on its way to realize its utopia.

During these years, the company also advertised its image as a strong supporter of the National Product Movement. Many of its activities demonstrated the desire to promote national products. For instance, Lianhua sent some of its stars to national product exhibitions (Shenbao, 26/11/1932, 16) or displayed some artefacts made for its films (LHHB, 1.14, 4; $1.16,2)$. The company also participated in the traveling national product exhibition going along the railroads (LHNJ 34-35, 24). Films were also screened for national event: such was the case in 1934 with Little Toys (Xiaowanyi, Sun Yu, 1934) scheduled to be screened at the opening of the Women's National Product Year in 1933 (Shenbao, 29/12/1933, 8). The 
climax came with the opening of Lianhua's museum in Shanghai. Described in November 1935's issue of Lianhua huabao, it displayed photos of its stars, costumes, props, settings, along with machines and showcased Lianhua's success and political, nationalist mission (LHHB 6.10, 15). The article in the journal highlighted this political dimension, writing that 'Chinese society in all its components is interested by Lianhua and more generally by National cinema' (14).

However, at that same time the company was facing a huge crisis that hits both its economic and social model.

If Lianhua promoted an image of a luxurious company with funds expected to reach one million (YXZZ 1.9) or much higher production costs than other companies, the reality was different. From the beginning, money was a problem. Producer Lu Jie recalls in his diary how Hong Kong shareholders never gave the promised funds (Lu 10/02/1931). The international situation had also some bad consequences. The Japanese invasion of Manchouria in September 1931 had forced the closure of the Beijing Studio while the company lost the studio Four, located in Zhabei, during the Battle of Shanghai in 1932. Money shortages were part of the everyday life of the company's producers who struggled to pay employees on time. Despite the efforts of the managers, the debts increased, reaching 230,000 yuan in February 1935 (Shanghai yinhang $\mathrm{n}^{\circ}$ 7265). By July 1935, the Company had so many difficulties paying its employees that it decreased their salaries and prepared to downsize (Shenbao, $21 / 07 / 1935,23)$. This was not enough and by the autumn, several projects were stopped because of the lack of funds. The crisis was at its peak ( $\mathrm{Lu} \mathrm{5/09/1935).}$

The company also struggled to establish unity among its partners and employees. The model of a community joined in a mission to help society and China with cinema as promoted in Two Stars was not easy to develop in the context of 1930's Chinese society. Because of political and artistic divergence, the two main Shanghai studios did not work well together. 
Rumors of a split occurred as early as 1932 when Studio One and Studio Two started to operate separately with distinct budgets, partly for financial reasons (Diansheng 4, 1; Diansheng 5, 2). The company did not escape social conflicts: relationships between managers and employees, some of them seduced by the communist ideas, were sometimes difficult. Many strikes occured. The company tried to organize regular meetings to discuss issues regarding management. However, the diary of the musician and composer Nie Er, who worked for Lianhua between 1931 and 1935 shows how some employees like him rejected the paternalistic model proposed (imposed) by Luo Mingyou that was perceived as capitalist exploitation (Nie 2004, 271).

The Lianhua social model also did not protect its employees, in particular its stars, from attacks of a still conservative Chinese society. The suicide of Ruan Lingyu in March 1935, as complex as it was, was not just an economic catastrophe. It was also a sign that despite its speeches about the good morality of the actors and actress from the film world, they were still vulnerable to rumors and cabals.

The move to Xujia hui and the opening of the Museum can be seen in a new light: concentration on a single location was a solution to the managerial problem and the financial crisis; efforts to participate in the National Product Movement was also a call for a governmental support that never came. ${ }^{5}$ None of the attempts saved Lianhua. The situation had deteriorated so much that by October 1935, some were worried that the Company was finished: 'Luo says that after the shooting of The Lost Lambs, Back to Nature, Waves Washing the Sand and Song for a Mother, we will stop the shootings, we will stop paying the salaries, we will only rent the location', writes producer Lu Jie in his diary (Lu 24/10/1935). The company had no other option than dramatic changes. Luo Mingyou resigned. A new structure and new management were built up between January and July 1936 and in operation as of August 1, 1936. It took the name of Hua'an and was directed by Tao Boxun and Wu 
Xingzai. Contracts with the filmmakers and other Lianhua employees were renegotiated with salary decreases as well as new production rules. One rule was that all films had to be talkies. During the entire time of the crisis and the transformation of Lianhua into Hua'an, the managers tried to keep the process secret. This was in part because the Company was hoping to borrow more money, which would be easier if nobody knew Lianhua's real situation (Lu 3/6/1936). But it was also important to keep the spirit of Lianhua alive. Rumors in newspapers and magazines described the end of the company and many strategies were employed to refute this. For instance, Li Minwei gave an interview in autumn 1936. According to him everybody was still at their post at Lianhua, the mission and the spirit of the company unchanged (Shanghai dongfang 13/9/1936). To reinforce this reassuring message, Lianhua's name stayed attached to the films produced and to the company's publication. The company was maybe a financial failure but it had succeeded in asserting its brand name. Films were also used to this end. Two in particular were collective films, deliberately conceived as 'a collection of outstanding specimens' ( $\mathrm{Lu} \mathrm{12/10/1936).} \mathrm{In} \mathrm{one} \mathrm{sense,} \mathrm{these}$ were also two new cinematographic portraits of the Company.

\section{A Film to Save the Nation (and the Company)}

We find no meta-films like Two Stars amongst Lianhua productions between 1932 and 1936. The economic crisis as well as management and political turmoil could explain this absence. However, two films, produced towards the end of Lianhua's existence, are proof that the company kept trying to advertise itself or, at least, to deliver its ideas about the place of movie industry in the nation building. The context of their production and their content equally shed light on the transformations the company had undergone over the years.

The crisis at Lianhua paralleled the national crisis with the Japanese threat to China. The Chinese society started to organize itself in patriotic associations and anti-Japanese 
demonstrations and Lianhua/Hua'an joined this movement. In October 1936, when the new structure had no more money to invest and no films were finished, the workers suggested producing a collective patriotic film made by the most famous filmmakers and actors of the company (Lu 6/10/1936). The film would be quick to produce and should bring fresh money: this is how Lianhua's symphony was made, illustrating the spirit of resistance and of continued solidarity of the community.

The film is a talking picture comprising eight shorts, made, among others, by Cai Chusheng, Fei Mu, Zhu Shilin and Sun Yu and played by Chen Yanyan, Li Lili, Li Zhuozhuo, among other stars. Each short has its own particular style and is very distinctive in itself. The film's sense of unity, however, comes from the history of its production as much as the patriotic message. According to Lu Jie's diary, its production followed a very tight schedule with a feeling of emergency: proposed on October 6, 1936, the scripts were reviewed on October 12 and the shooting of the first short started ten days later. Work was intense, lasting sometimes

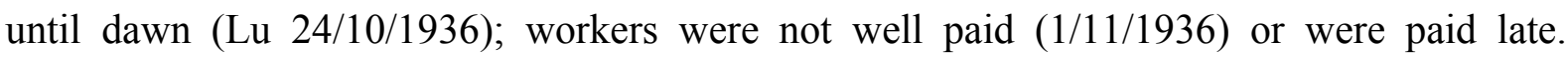
However, exactly two months after the beginning, the shoot was over leaving only postsynchronization work.

The film was promoted in the first issue of Lianhua huabao of 1937 as a 'Lianhua glorious contribution' and a 'concerted effort of all the actors; a production of all the filmmakers' (LHHB 8.4, 13). The opening of the film captures this united spirit. Filmed by Fei Mu, after the name of Lianhua appears on screen, the scene shows the troupe of the actors and filmmakers who made the film, singing a song together with the background of the white walls of the Company's hall. Self-referentiality is enhanced by the song, the 'Song of the road' (Dalu ge), which came from a previous film by Sun Yu, produced at Lianhua in 1934 and written by the late Nie Er. At the end of the song sequence, the camera moves backward to actually show the cameras: the Lianhua company is presented as a team of fighters, ready 
to resist the enemy with its tool, cinema. The opening of Lianhua's Symphony shows how the film company still wants to be seen as a national model: but this time, a model of patriotism and the spirit of collective effort. As the double page presenting the photos of the singing group says: 'we are the vanguard that opens the road' (idem).

(Fig. 4)

This opening is also the only self-referential moment in the film. It proposes a different depiction of the movie world (and the society) than that of Two Stars. The horizontality of the social relations is striking: no film director or producer is supervising the work. The employees are dressed in very casual costumes, presenting themselves as workers of the film industry and not as a group of elegant entrepreneurs. The ideology is different and this sequence functions almost as a counter utopia. The absence of the producers or film director illustrates an ideal of an equalitarian community, but could also signal the real split in the company between the bosses and the employees. The only common them left is the presentation of a collectivity ready to serve China with its art. The question becomes: what sort of collectivity?

\section{The Last Portrait}

The last self-portrait of the company sheds new light on this question. It was produced few months after Lianhua Symphony, between March and June 1937.6 Made again to rescue the company from financial troubles, war broke out before the film was released. ${ }^{7}$

Even if it was qualified with the same words than for Lianhua Symphony, as a 'collection of outstanding specimens', and even if there was the idea of making a film similar to the Symphony in its collective spirit (the film first title was Lianhua March, see Dianying zhoubao, 2.11, 11), A Sea of Talents differs greatly from the previous opus. The context of its production is part of the explanation. But the three stories that composed the film are also 
very different, far from the vibrant call to patriotism of Lianhua Symphony.

The project of making a new collective film was born in February 1937, when the Hua'an company and its new directors launched the production of many talking films in spite of fragile finances. The diary of Lu Jie, who remained in place, reveals a struggle between those who pushed for spending and those who wished on the contrary to restrict the budgets. The latter view finally seemed to prevail, probably out of realism, as money was so scarce: 'It's like going to war without anything in your hands!' complained Lu Jie during the shootage of A Sea of Talent (Lu 1/6/1937). A few days before, the decision had been made to limit the number of meters of film that could be used daily for each film ( $\mathrm{Lu}$ 29/5/1937).

Do these financial matters, recurrent and probably wearing for the directors of the company, or deeper differences between the employees of the Hua'an and this new management explain the defection of two out of the five directors planned fort the film? First, Sun Yu declared on February 18 that he would not participate in the project. The film is then accepted by the script committee in mid-March (Lu, 16/03/1937) and presented in the press (Dianying zhoubao, 2.11, 11) with four directors: Zhu Shilin, Fei Mu, He Mengfu and Situ Huimin. But in the end, Fei Mu disappears also. The reasons for the defection of another key director remains obscure: did he lose too much time to finish his previous film, Zhan Jintang? Were there more personal reasons? In the course of May, Lu Jie mentions family problems that force Fei to ask for a leave of absence. On May 25, the producer meets with the three remaining directors to discuss 'how to finish the film' (Lu, 25/05/1937).

The group assembled to make this film is thus reduced to a small number. We are far from the eight pieces composing the Lianhua Symphony. Nothing in the pages of Lu Jie's diary or in Lianhua huabao suggests that the same spirit of mobilization has galvanized the employees. And even though the press announced the presence of the company's big stars, it also reported on the dissensions between the director Situ Huimin and Lianhua. In fact, the director made 
official his decision to leave the company to join Xinhua in May, while he was in the middle of shooting his short for $A$ Sea of Talent, which was therefore also his last work for the company ( $Y i$ yu Xi, 1.25, 387). Clearly, the collective spirit had a hard time to exist.

The content and form of the film also differ from Lianhua Symphony. The latter could be described as a joyful eclecticism of genres, forms, and narrative content, with the same injunction, the call to mobilize consciences in defense of the homeland. A Sea of Talent has a single theme, the art world, or, as Lianhua magazine puts it, 'the life of the stage' (LHHB, 9.6, 14). It depicts in three shorts the life and work of artists in the film industry ( $A$ Cinematographic City, Dianying cheng, by Zhu Shilin), or as a theater writer (A Drama, Tuan juhua, He Mengfu) or as dancers (A Musical Troup, Gewu ban, by Situ Huimin). The first and last films can be described as comedies while the central film is much more dramatic. It also differs formally, with an influence of expressionism style.

While the film was shot a few months before the Japanese invasion, the political message seems absent from the three films. If there is a political message, it is less about the Japanese threat than about the future of a societal project and the role of art in it. The film opens with $A$ Cinematographic City. A true meta-picture, it shares with Two Stars the pedagogical aim to present the shooting of a film in detail. But the utopia carried in Two Stars is gone, put to the test of reality. Visually, the movie world is not anymore presented as an elegant activity set in a luxurious environment. Neither is the presence of Chinese elements so heavy: the film on shoot has no connection with the classical culture. At the beginning of the film, the camera moves in a film set. No group portrait is offered; instead there is a succession of shots on the different aspects of the shootings. The film is shown as a process based on peculiar mastery of several techniques: the sound technique, the lighting, the camera, the acting, the make-up. The film director is turning his back to the camera, distributing his instruction to everybody but is never showed with all is colleagues all together. 


\section{(Fig. 5)}

While in Two Stars shooting is a harmonious moment, in A Cinematographic city it turns out to be chaotic. The scene on set is a scene of catastrophe: a house is under fire, during a violent storm, and its inhabitants are trapped in it. The images of destruction and danger echo with another film, that was produced at the same time at Lianhua, Fifth Brother Wang (Wang Laowu), describing the 1932 war in Shanghai. Filming is not anymore about transmitting traditional Chinese art and culture; it is the reconstitution of a harsh reality, the evocation of people's misfortunes.

In the studio also, harmony is gone. The main female actress, Miss Wang (Gong Zhihua) refuses to play, because she has to jump into a burning house to save some children and then faint into the mud while a tree would fall next to her. She does not want to 'risk her life for so little money'. Then, the producer and the director disagree: the first one has put already a lot of money into the production and wants to keep the actress, a big star that will bring many fans, even if it means to adapt the story for her, the director refuses to bend to her whims. At the end, the film resumes thanks to a young woman, Lu Lin (Li Zhuozhuo) who places her passion for acting above everything else and is able to convince, through a trick, the film director that she is the right person for the role.

The movie world is presented as a complex, chaotic, world. A Cinematographic City also questions frontally the issue of the social status of film actress. The film offers portraits of two actresses. The first one, Miss Wang, is the star, presented as a well-paid, yet selfish personality, indulging in a comfortable life. She has no sense of collectivity, and is accused by the director to 'cause harm to the all team' by refusing to play in the scene.

The other, Lu Lin, is a gifted woman ready to sacrifice her personal life for her passion: being an actress. Summoned to choose between a marriage and the movie career, as it is clearly stated that an actress cannot be considered as an honorable spouse, she chose her career. In 
the end, luckily, she will have both. How much, however, this portrait was drawn by people from the company concerned by the fascination exercised by this profession on young naive girls or disillusioned after the suicide of Ruan Lingyu, attacked because she was a film actress and as such considered as a "bad woman"? While in Two Stars the story makes believe that a girl like Yueh Ying can work and be protected in a film company, A Cinematographic city, shows the actress as a young, independent woman from a modest background who has a hard time to move up in her chosen career and can count only on herself.

The question of talent is also raised: in acting, luck and gifts are not sufficient. Lu Lin is not chosen by the production, like was Yueh Ying. She finally enters the career thanks to her stubbornness, spirit of self-sacrifice as well as her capacity to act, to transform her body and voice. Elegance is gone: to persuade the film director to hire her, Lu Lin dressed up herself as an old, poor and unattractive lady. In the final scene, she will finally play the leading role, that of a common woman who rescues a family in a house on fire. Torn clothes, wet hair, face black with smoke: this is the new film actress according to Lianhua, far away from the beautiful photos of the magazines covers.

With the disagreement between the producer and the film director, another important message emerges: the power of money, the battle between art and finance. This is a common thread that runs through all the shorts of $A$ Sea of Talent. In A Drama, the writer dies sick and poor, while the actors are repeating his play. The last image shows the shadow of a strong man, smoking a long cigarette, behind a glass door labeled jingli shi (Accountant's Office). And the number of banknotes he is counting show the play was a success. In A Musical Troupe money also wins and moral and virtue, the key values highlighted by Lianhua, are washed away. After many ups and downs, the Huahua troupe ends up playing a program, Pleasure of the Flesh (Chunyan rougan), where the girls show their legs, instead of Spring's Glow (Chunguang mingmei), the more artistic play first planned. The public, stage manager and 
theater manager are all satisfied. Left alone, the unfortunate author leaves the theater. The money had subverted the artistic and moral mission of cultural enterprise.

(Fig. 6)

A Sea of Talent film describes three situations where artists need to negotiate with money. But if the film as a whole makes the bitter observation that the world of entertainment and art is corrupted by the financial powers, A Cinematographic City also suggests that in cinema, it is still possible to find a form of balance, of which the Lianhua company would be a kind of model.

This balance is achieved first of all by questioning the star system. We know that the company never recovered (financially in particular) from the disappearance of its main star, Ruan Lingyu. Afterwards, no Lianhua actress reached this level of fame. A Cinematographic City suggests a solution to this problem: to stop relying on the star system, but rather to seek out real talent dedicated to their art.

Let us notice secondly that the financial question is not central in A Cinematographic City. The company is here faithful to its policy, seeking to minimize its financial problems. But by the time $A$ Sea of Talent was filmed, these problems had become well known and many in the press saw Hua'an as an association of shareholders without artistic culture, having vampirized Lianhua and killed its ambition while making it sink into heavy debt. In May 1937, Luo Mingyou had to refute these rumors. He described Hua'an as a 'friendly' company that had come to rescue Lianhua, allowing it to 'escape its debtors' (LHHB, 9.3). In reality, Lianhua was in debt to Hua'an (Shanghai yinhang no. 16628). But it was vital to keep the soul of Lianhua alive, with its mission in the service of the nation. A Cinematographic City, by evacuating the financial question, and by making the figure of the producer disappear thus answers in its own way to the rumors: it is the duet between the director and the actress that is central, suggests the film. If there is talent, love of art, if the spirit of sacrifice remains, the 
financial question can be evacuated.

Finally, it should be noted that the film that is shot is not a simple entertainment but a film evoking with realism the misfortunes of fellow citizens. In the scene that is shot, the specter of war is evoked, threatening the people. The extras in this scene are also the people, people who, as Miss Wang says, put themselves in danger 'because they have no choice, they need to eat'. A Cinematographic City affirms then the strong connection between cinema and the people. If the utopia is gone, the social and political ambition that founded Lianhua has not disappeared. It transpires in the contrast between the world of cinema and that of the musical or theatrical scene: the latter are either totally corrupted by the mercantile spirit of entertainment, or paralyzed by their own ideals. Cinema, on the other hand, can continue to speak of the people, with the people, for the people. As such, this art has still a social and political role to play.

\section{Conclusion}

In December 1946, just after the war, a journalist went on a tour of Xujia hui's studio, and described as the place "where Lianhua has grown and shone brightly. It was here that the foundations were laid for his ambitious project to save the film industry' (You 1947). A film is being shot: Eight Thousand Li of Clouds and Moon (Baqian li lu yun he yue), then presented as a film made by 'The Society of Film Art Lianhua'. This film, that was finally produced by Kunlun, as the new Lianhua failed to survive, became one of the biggest postwar box office successes. It was realized by Shi Dongshan, the director of Two Stars. Yet the style and message of the film could not be more different. Even the production and shooting process were different, described as a 'collective' and 'democratic'. The director, notes the journalist, 'wears a grey cloth workwear' and 'could easily be mistaken for a little set technician' (idem). 
War has passed, and another project was being prepared for China as well as the art world. The utopia that was at the beginning of the company was long gone. It is, however, striking to see Lianhua's name associated still with more than just the film industry. Until the end, the company was known for its vision, its cultural and social mission, all linked, if not tied up, to the destiny of the Nation.

The three films studied here served as a communication vehicle for the company and helped it to publicize its identity and the hopes of the ones who made the company. Through the magazine articles and photos, or the films, Lianhua was shown as a microcosm that could serve as a model for Chinese society. The films therefore also served as a vector for the vision, the political and social project nurtured at Lianhua by founding members, its producers, and some of its employees.

These projects evolved as well as the destiny of Republican China. Two Stars, Lianhua Symphony and A Sea of Talent offer three contrasting portraits of what a movie company is or should be as well as evolving visions of the Chinese Nation.

Two Stars deals with issues regarding the Chinese identity that were central in the early 1930's, questioning the role of traditional Chinese culture and westernization, the social and political importance of culture and the leading role of educated (including artistic) elite. The film also sends a strong message to the new government by advocating a harmonious, nonconfrontational society. The most utopian part of the film, and of Lianhua's project, undoubtedly resides in this vision.

Like many utopias, this one was bound to remain in a virtual state. The Lianhua Company was hit hard by the crises that the country faced between 1931 and 1937 , in addition to its own internal problems. The ideal of a harmonious collective was constantly undermined in an increasingly divided society. The microcosm that was the company for real was also caught in the turmoil. 
Lianhua Symphony is an attempt by a group of people to come together around a higher common goal, the defense of the homeland as well as the survival of their company. Was this a higher goal or the only cement that could still hold together a divided and weakened community? The opening portrait is very different from the on-set photography of Two Stars, if only because the producers and founders of the company are not in the picture. This sequence is not fiction but is not totally true neither. The image of an egalitarian team without any director or manager may have been the dream of some of Lianhua's artists. Yet, it was not the reality of the company management. By an irony of fate, this image ended up surviving the war to become the final vision of a company that never restarted.

Lianhua last self-portrait, A Cinematographic City, reveals how the company has undergone a transformation. It underlines the change in perception of Chinese social reality and of national identity. First, it seems that the missions assigned to cinema, and by extension, to the cultural world, are less ambitious, or rather less idealistic. There are no more overhanging preaches from producers or directors about the central mission of culture. Second, the collective at work in A Cinematographic City is no longer the homogeneous community of Two Stars. Rather, it is a group of individuals from different social classes who are gathered to work together. Conflicts of interest (that of the star, Miss Wang, that of the director, that of Mr. Li, a traditional man worried about marrying his son to an actress) are legion and the film must be made with them as much as in spite of them.

But the film is not nostalgic. For, if the harmony has disappeared, the tensions can also be solved. Some of them, very present in Two Stars, have thus disappeared. This is the case of the opposition between Chinese culture, its traditions, its values and Western culture. It structured Two Stars but is not a subject of debate in A Cinematographic City. On the contrary, we see Mr. Li, a man of traditional values as we understand it from his clothing, evolve, not only accepting that his son can marry an actress, but even suggesting he could, 
himself, play a role in the film. The role of women has changed, also: Lu Lin decides her own destiny, regardless of what men may think, and can escape from the patriarchal world.

Certainly, this last self-portrait of Lianhua reveals its failure to be a model for the Chinese nation. A Sea of Talent as a whole highlights the crisis faced by the world of arts and culture, which is subject to financial issues and diverted from its political missions. However, $A$ Cinematographic City manages to propose a new idea of cinema, and of the role of cinema in the society. It is shown as an art made with the people as much as for them. In the end, this film affirms the unifying power of cinema, its capacity to accomplish its goals despite the individual differences and the upheavals of any collective work. If utopia has disappeared, hope in cinema remains, a hope that will resonate until after the war.

\section{Notes}

For a study of this film, see Harris (2012), pp. 191-244. Harris' article gives a complete analysis of the film and the novel it is based upon, and provides details about the sound technology. My study here takes another angle, though not contradictory to Harris, by focusing more on the connection between the film and the moment of its production.

${ }^{2}$ Lianhua had four studios at the beginning. Studio Two was previously the Da Zhonghua Baihe company.

${ }^{3}$ On the U.P.S. Follies and Li Jinhui, see Harris (2012), p. 195 and Jones (2001), pp. 97-99.

${ }^{4}$ Apart from the three films discussed her, we identified the following: Film Star (Dianying nümingxing, 1926); An Actress in Love (Duoqing de nüling, 1926), Flower of the Silver Screen (Yinmu zhi hua, 1929), An Amourous History of the Silver Screen (Yinmu yanshi, 1931) Silver Star Luck (Yinxing xingyun, Mingxing, 1931), A Film Star (Yige nümingxing, 1933). On An Amourous History of the Silver Screen, see Zhang (2005), pp. XIXXXVIII.

${ }^{5}$ Luo Mingyou and Li Minwei took a trip to Nanjing in May 1936, to request financial support from Chen Lifu. The trip was a failure (Li Minwei 2003, 21).

${ }^{6}$ According to Lu Jie diary.

${ }^{7}$ The film is announced in Lianhua huabao 9.5, July $1^{\text {st }}, 1937$ and again in the following and last issue of August 1937 but according to my research in Shenbao it was not released before the Japanese attack on Shanghai. 


\section{Declaration of interest statement}

No potential conflict of interest to report

\section{References}

Ames, Christopher. 1997. Movies About the Movies: Hollywood Reflected. Lexington: University Press of Kentucky.

Baczko, Bronislaw. 1978. Les Lumières de l'utopie. Paris: Payot

Ban Xiang. 1932. "Shuang xing shi wu ji”, The Film Magazine (Yingxi zazhi), 2.3: 30-31.

Bloch, Ernst. (1959) 1995. The Principle of Hope. Volume One. Cambridge MA: The MIT Press.

Bordwell, David, Janet Staiger and Kristin Thomson. 1985. The Classical Hollywood Cinema, Film Style and Modes of Production to 1960, London, New York: Routledge.

Cieutat, Michel. 1984. « La star au miroir ou le syndrome romain (de Show People, 1928, à Frances, 1982) », Revue Française d'Études Américaines, 19 : 61-75.

doi : https://doi.org/10.3406/rfea.1984.1157

Diansheng ribao - Radio Movie news, $\mathrm{n}^{\circ} 4$, 4/5/1932, p. 1; $\mathrm{n}^{\circ} 5$, 5/5/1932, p. 2: "Lianhua gongsi buxing neibu da polie"

Dianying zhoubao, n².11, 27/3/1937, p. 11, "Fei Mu, He Mengfu, Zhu Shilin, Situ Huimin, lianhe daoyan Yihai fengguang quanti heyan"

Gao Shan. 2009. "Shi lun zuo wei baihua xiandai zhuyi de Yinhan shuang xing”, Dangdai dianying 1: 38-39.

Gerth, Karl. 2003. China Made. Consumer Culture and the Creation of the Nation. Cambridge (MA), London: Harvard University Press.

Harris, Kristine. 2012. "Two Stars on the Silver Screen: The Metafilm as Chinese Modern", in History in Images. Pictures and Public Space in Modern China, edited by Christian Henriot and Wen-hsin Yeh, 191-244. Berkeley: University of California.

Henriot, Christian and Wen-Hsin Yeh. 2013. "Introduction. China Visualised: What Stories do Pictures Tell?", in Visualising China, 1845-1965: moving and still images in historical narratives, edited by Christian Henriot and Wen-hsin Yeh, vii-xxvi. Leiden, Boston: Brill.

Ivakhiv, Adrian. "Cinema of the Not-Yet: The Utopian Promise of Film as Heterotopia". Journal for the Study of Religion, Nature and Culture, Vol 5, No 2 (2011), 186-209. 
Jones, Andrew F., 2001.Yellow Music, Media Culture and Colonial Modernity in the Chinese Jazz Age. London, Durham: Duke University Press.

Li Minwei. 2003. Li Minwei riji - The Diary of Lai Man-wai, Li Xi (Lai Shek) (coll.). Hong Kong: Hong Kong Film Archives.

LHHB: Lianhua huabao, Shanghai, Lianhua yingye gongsi bianyi bu

1.14, 2/4/1933, 4 : "Lianhua canjia Jiaoda zhanlan hui- Lianhua participates in the Jiadong University exhibition"

1.16, 16/4/1933, 2 : "Zhanlan hui xiao ji- About the exhibition"

2.21, 19/11/1933, 2, "Lianhua gedi zhipian chang- Lianhua locations of its films studios"

5.6, 16/03/1935, 7, "Lianhua banyue lai- Lianhua news for the next two weeks"

6.8, 15/10/1935, 13 "Lianhua nei jing- Inside Lianhua"

8.4, 1/1/1937, 13 "1937 nian Lianhua zhi rongyu gongxian”

9.3, 16/51937, "Lianhua gongsi minguo 25 nian du zhuangkuang gaobao shu"

9.6, 1/8/1937, 14, "Lianhua shengwei”

LHNJ 33-34: Lianhua nianjian 1933-34, Shanghai, Lianhua yingye gongsi bianyi bu, 1934

"Lianhua chengli zhi jingguo - History of the United Photoplay Services Ltd": 2-4

"Lianhua zhi di yi pian xuanyan - The first statement of the U.P.S": 5

"Lianhua zhi zongzhi ji gongzuo - Objects and Functions of the U.P.S": 6

"Lianhua da shiji - U.P.S. Events":12-17

"Lianhua julebu - U.P.S. Recreation Clubs": 58

LHNJ 34-35: Lianhua nianjian 1934-35, Shanghai, Lianhua yingye gongsi bianyi bu, 1935

"Lianhua da shiji": 23-28

Lu Jie riji, unpublished, courtesy of Chinese Film Archives

Manuel, Frank E. \& Manuel, Fitzie P. 1979. Utopian Thought in the Western World. Cambridge (MA): The Belknap Press of Harvard University Press

Nie Er. 2004. Nie Er riji. Zhengzhou: Daxiang chubanshe.

Shanghai dongfang ribao, 13 juin 1936: "Yi you zanshi jiuji ban. Lianhua zhaochang jixu liang xin pian gongzuo. Zhuan Li Minwei you chongxin hezuo shuo"

Shanghai yinhang $\mathrm{n}^{\circ} 7265$, "Lianhua yingye zhipian yinshua gufen youxian - The United Photoplay Service Co. Ldt. Di er ci diaocha”, published on 25 February, 1935. Shanghai Municipal Archives, 66.

Shanghai yinhang $\mathrm{n}^{\circ}$ 16628: "Shanghai yinhang jingli xiansheng. Di 16628 hao. Lianhua yingye zhipian yinshua youxian gongsi di si diaocha", 28/10/1938. 
Sun Yu, Yinhai fanzhou, Shanghai, Shanghai Wenyi chubanshe, 1987.

Trousson, Raymond. 1998. D’utopie et d'utopistes. Paris: L'Harmattan.

Yi yu Xi, 1.25, 27/5/1937, p. 387, "Xinhua jiangjin mengjiang"

Yingxi zazhi -The Film Magazine, 1.9, august 1930: "Chuangban Lianhua yingye zhipian yinshua youxian gongsi qishi"

You Ming. 1946. "Lianhua dianying gongsi zhipian chang xunli”, Yingyi huabao, 1946.1

Zhang Zhen. 2005. An Amourous History of the Silver Screen, Shanghai Cinema, 1896-1937.

Chicago, London: The University of Chicago Press. 


\section{Figures}

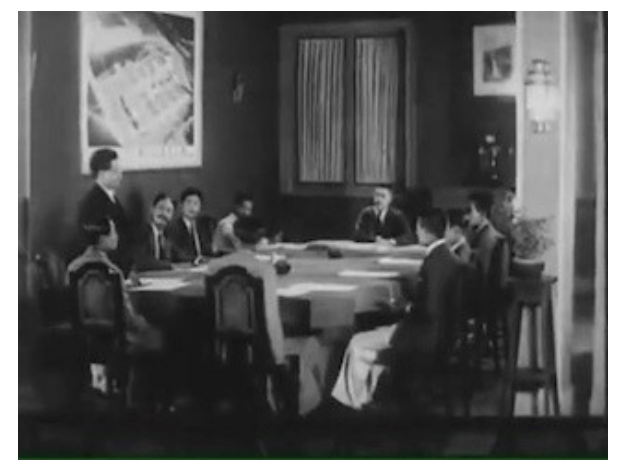

Fig. 1: Screen capture of Two Stars of the Milky Way: meeting at Yinhan

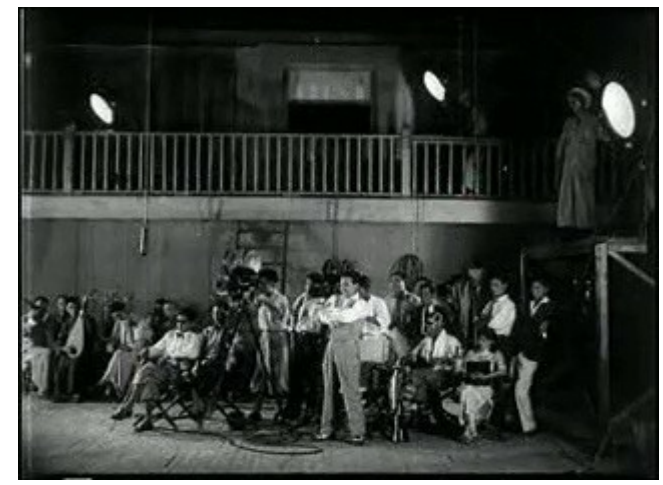

Fig. 2: Screen capture of Two Stars: shooting of Sorrow in the eastern Chamber

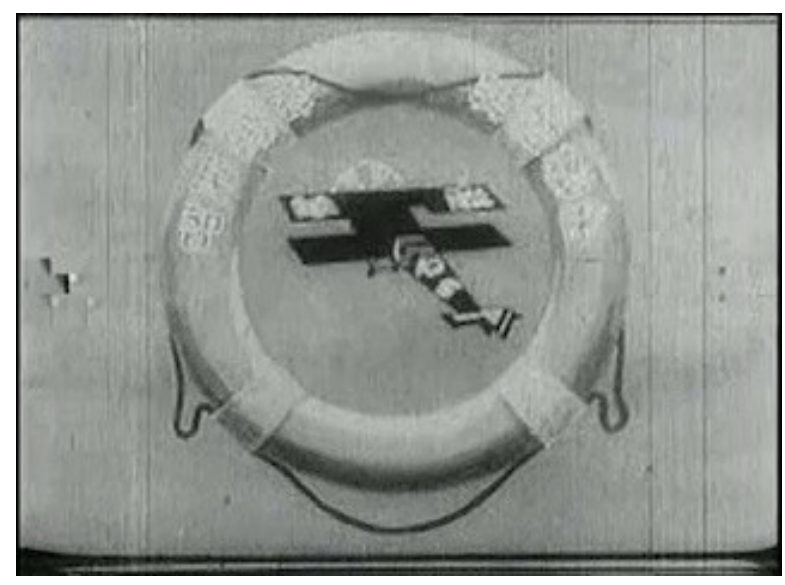

Fig. 3: Screen capture of Two Stars of the Milky Way: Lianhua logo 


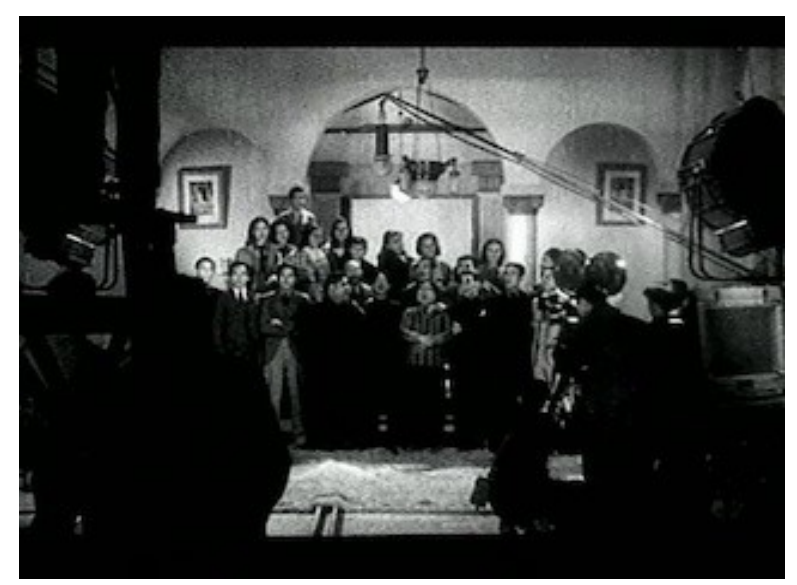

Fig. 4: Screen capture of Lianhua Symphony, opening scene

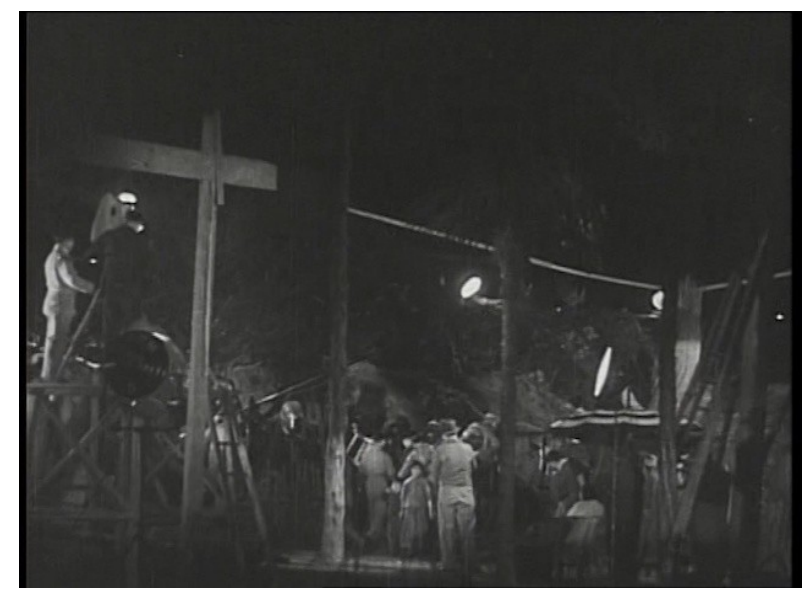

Fig. 5: Screen capture of $A$ Cinematographic City, opening sequence. The film set with the director (in the middle with a hat) giving instruction to a boy actor.

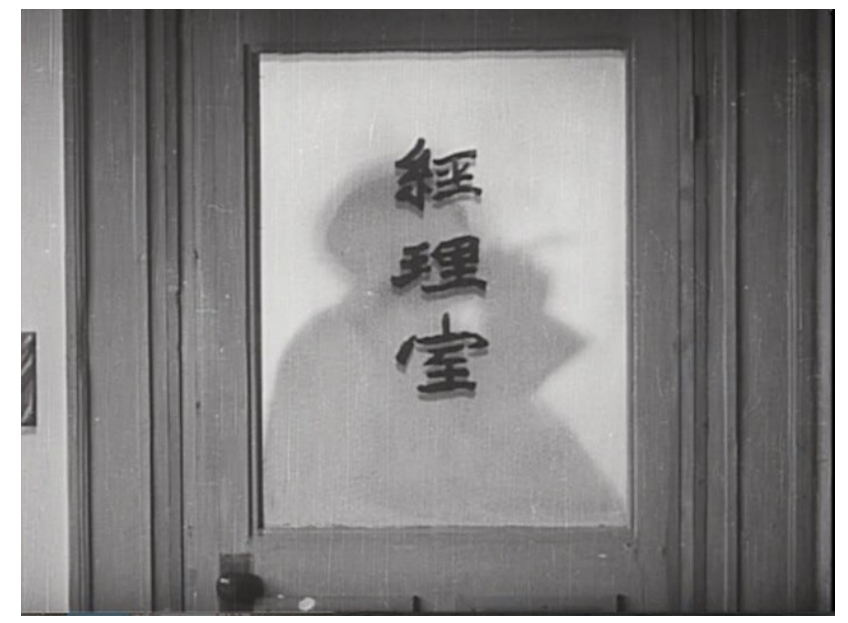

Fig. 6: Screen capture of A Drama, last image: The Accountant's Office. 


\section{Figures caption}

Fig. 1: Screen capture of Two Stars of the Milky Way: meeting at Yinhan

Fig. 2: Screen capture of Two Stars: shooting of Sorrow in the eastern Chamber

Fig. 3: Screen capture of Two Stars of the Milky Way: Lianhua logo

Fig. 4: Screen capture of Lianhua Symphony, opening scene

Fig. 4: Screen capture of $A$ Cinematographic City, opening sequence. The film set with the director (in the middle with a hat) giving instruction to a boy actor.

Fig. 6: Screen capture of A Drama, last image: the Accountant's Office. 
